\title{
ABBREVIATIONS AND FOOTNOTING
}

Standard abbreviations are used in footnoting archival sources: f. $=$ fond [collection], st. $=$ stol $[\mathrm{desk}] ;$ ot. $=$ otdelenie $[$ section or division]; op. $=$ opis' [list]; sv. = sviazka [bundle]; d. = delo [file] (plural: dd.); l. = list [sheet or page] (plural: 1l.); ob. = oborotnaia storona [verso].

Frequently cited archives, journals, newspapers, and other works have been abbreviated as follows:

$\begin{array}{ll}\text { AHR } & \text { American Historical Review } \\ \text { EtnogO } & \text { Etnograficheskoe obozrenie } \\ \text { GARF } & \text { Gosudarstvennyi Arkhiv Rossiskoi Federatsii } \\ \text { GARO } & \text { Gosudarstvennyi Arkhiv Riazanskoi Oblasti } \\ \text { IaGV } & \text { Iaroslavskie gubernskie vedomosti } \\ \text { IAOiRS } & \text { Izvestiia Arkhangel'skogo Obshchestva izucheniia Russkogo Severa } \\ \text { ISSSR } & \text { Istoriia SSSR } \\ \text { IuV } & \text { Iuridicheskii vestnik } \\ \text { IuZh } & \text { Iuridicheskii zhurnal } \\ \text { IV } & \text { Istoricheskii vestnik } \\ \text { JGO } & \text { Jahrbücher für Geschichte Osteuropas } \\ \text { JIH } & \text { Journal of Interdisciplinary History } \\ \text { JMH } & \text { Journal of Modern History } \\ \text { JSH } & \text { Journal of Social History } \\ \text { LSR } & \text { Law and Society Review } \\ \text { KD } & \text { Krest'ianskoe dvizhenie } \\ \text { MosVed } & \text { Moskovskie vedomosti }\end{array}$


MVD Ministerstvo Vnutrennykh Del (Ministry of Internal Affairs)

NizhL Nizhegorodskii listok

Otchety Otchet Ministerstva Iustitsii

OrlV Orlouskii vestnik

PSZ Polnoe sobranie zakonov

PV Povolzhskii vestnik

RB Russkoe bogatstvo

RGIA Rossiiskii Gosudarstvennyi Istoricheskii Arkhiv

RIAMZ Riazanskii Istoriko-Arkhitekturnyi Muzei-Zapovednik

RiazEV Riazanskie eparkhial'nye vedomosti

RiazGV Riazanskie gubernskie vedomosti

RiazV Riazanskii vestnik

RiazZh Riazanskaia zhizn'

RR The Russian Review

RSP Rukovodstvo dlia sel'skikh pastyrei

RusM Russkaia mysl'

RusRech' Russkaia rech'

RusVed Russkie vedomosti

SAA

Soviet Anthropology and Archeology

SarGV Saratovskie gubernskie vedomosti

SbNIuO Sbornik narodnykh iuridicheskikh obychaev

SbSiBKNR Sbornik svedenii dlia izucheniia byta krest'ianskogo naseleniia Rossii

SbSSMIu Sbornik statisticheskikh svedenii Ministerstva Iustitsii

SbSSMPPS Sbornik sochinenii po sudebnoi meditsine, sudebnoi psikhiatrii, meditsinskoi politsii, obshchestvennoi gigiene, epidemiologii, meditsinskoi geografii $i$ meditsinskoi statistike

SE Sovetskaia etnografia

SEER Slavonic and East European Review

SevK Severnyi krai

SevV Severnyi vestnik

SimbGV Simbirskie gubernskie vedomosti

$\mathrm{SPb} \quad$ St. Petersburg

SPbVed Sankt-Peterburgskie vedomosti

SR

Slavic Review

SudG Sudebnaia gazeta

SudO Sudebnoe obozrenie

SudZh Sudebnyizhurnal 
SV

Svody

SZU

TambGV

TiurV

TsGIAgM

Trudy

TrudyIVEO

Trudy MKNSP

VE

VestP

VOGSP

VolzhV

ZhGUP

ZhivRus

ZhivSt

ZhMIu

ZhUPP
Sel'skii vestnik

Svod Statisticheskikh svedenii po delam ugolovnym

Svod zakonov ugolovnykh

Tambovskie gubernskie vedomosti

Tiuremnyi vestnik

Tsentral'nyi Gosudarstvennyi Istoricheskii Arkhiv goroda Moskvy

Trudy komissii po preobrazovaniiu volostnykh sudov

Trudy Imperatorskogo vol'nogo ekonomicheskogo obshchestva

Trudy mestnykh komitetov o nuzhdakh sel'skokhoziaistvennoi promyshlennosti

Vestnik Evropy

Vestnik prava

Vestnik obshchestvennoi gigieny, sudebnoi i prakticheskoi meditsiny

Volzhskii vestnik

Zhurnal grazhdanskogo $i$ ugolovnogo prava

Zhivopisnaia Rossiia

Zhivaia starina

Zhurnal Ministerstva Iustitsii

Zhurnal ugolovnogo prava $i$ protsessa 
